\title{
A Non-Linear Analysis of the Oil Price-Exchange Rate Nexus in Nigeria
}

\author{
Olagbaju Ifeolu O., Akinbobola Temidayo 0. \\ Obafemi Awolowo University, Nigeria \\ ifeoluolagbaju@gmail.com; iolagbaju@oauife.edu.ng
}

\begin{abstract}
This paper studies the effect of oil price shocks on the Nigerian exchange rate on the basis of monthly data over the period January, 2008 to October, 2015. In order to explore the effects of oil prices on the competitiveness of the Nigerian currency, which had hitherto attracted little attention in literature, the paper adopts the real effective exchange rate measure within a five-variable VAR model, analysed using both linear and non-linear approaches. We find evidence of a non-linear impact of oil prices on real effective exchange rate. Specifically, decreases in oil price are found to have an appreciating impact on real effective exchange rate, implying a loss of competitiveness of the Naira, while increases in oil price are found to be irrelevant for movements in the real effective exchange rate. Our study also suggests a link between Naira depreciation and the real effective exchange rate appreciation through a pass-through effect on rising domestic prices.
\end{abstract}

Keywords: Oil price shocks; real effective exchange rate; Non-linear specification; Vector autoregressive model; Granger causality

\section{Introduction}

Crude oil exports account for a large proportion of the Nigerian government revenue. Consequently, the variability in prices of oil is expected to have a significant impact on the country's exchange rate, given the (managed) float exchange rate system adopted in the country. Theoretically, increases in oil price should cause an increase in the oil exporting country's foreign reserves, the effect of which is an appreciation in nominal exchange rate. Conversely, reduction in oil prices should result in a nominal depreciation of the currency. ${ }^{1}$ However, the nominal exchange rate might not adequately capture the terms of trade given the reaction of other macroeconomic variables to falling output. For instance, countries which are largely dependent on imports for consumption of goods and services are prone to exchange rate transmission effects on local prices (An and Wang, 2011; Aliyu et al., 2009). ${ }^{2}$ Particularly, despite the status of Nigeria as a netexporter of crude oil, the country's heavy dependence on imports of refined petroleum to meet her energy needs, coupled with the inflationary effect of the scarcity experienced in the domestic energy markets, could reverse the trends observed in the nominal depreciation of the exchange rate as evidenced by the appreciation of the real effective exchange rate (REER).

Figure 1 showcases the loss of competitiveness in the Nigerian exchange rate as evidenced by the plummeting (appreciation) of the real effective exchange rate $^{3}$ despite the consistent rise (depreciation) in the nominal exchange rate. While the official and parallel market rates have increased from NGN118/USD and NGN121/USD in January 2008 to NGN197/USD and NGN225/USD, respectively in October 2015, the real effective exchange rate has taken a steady fall from NGN99.45/USD to NGN61/USD over the same period. The widening disparities between the official and parallel exchange rates, particularly since January 2015, should have appreciable implications for domestic prices. The exchange rate dynamics in the face of falling oil prices therefore raise curiosity as to the association between oil prices and movements in exchange rate. Oil prices have fallen dramatically by as much as 70 percent since June 2014 and hitting a low of $\$ 26$ per barrel in February 2016. The status of Nigeria both as a net exporter of crude oil as well as net importer of refined oil

\footnotetext{
${ }^{1}$ Krugman (1983) and Corden (1984) have contributed to the theoretical literature on this relationship.

${ }^{2} \mathrm{An}$ and Wang (2011) and Aliyu et al. (2009) find evidence of pass-through in exchange rate for import and consumer prices.

${ }^{3}$ This is a trade-weighted index of the average value of the country's currency computed in real terms (Appleyard and Field (2001). Our definition is such that a decrease (increase) translates to a real appreciation (depreciation) of the Nigerian currency (NGN). A real appreciation of the effective exchange rate is expected to negatively affect the competitiveness of the nation's currency.
} 
products posits a puzzle as to the significance of oil price changes. On one hand, dwindling revenues have enforced currency depreciation in the interbank market and, especially, in the parallel market; while contrariwise, trends in the real effective exchange rate reveal the appreciating effect probably resulting from rising domestic prices. Thus, this study seeks to analyze the relationship between oil price shocks and real effective exchange rate in the period 2008(M1) and 2015(M10). The study period is instructive given the preponderance of financial crises experienced globally since 2008. This scope allows us to further determine the effect of oil price changes on the Nigerian exchange rate in view of previous studies such as Olomola and Adejumo (2006); Aliyu (2009); and Adeniyi et al. (2012). Ultimately, the competitiveness of the Naira against trading partners' currencies is exploited in our study, given the adoption of the real effective exchange rate as against previous studies that have explored the discussion in the Nigerian context based on the real exchange rate.

Figure 1: The Nigerian exchange rate - 2008M1-2015M10

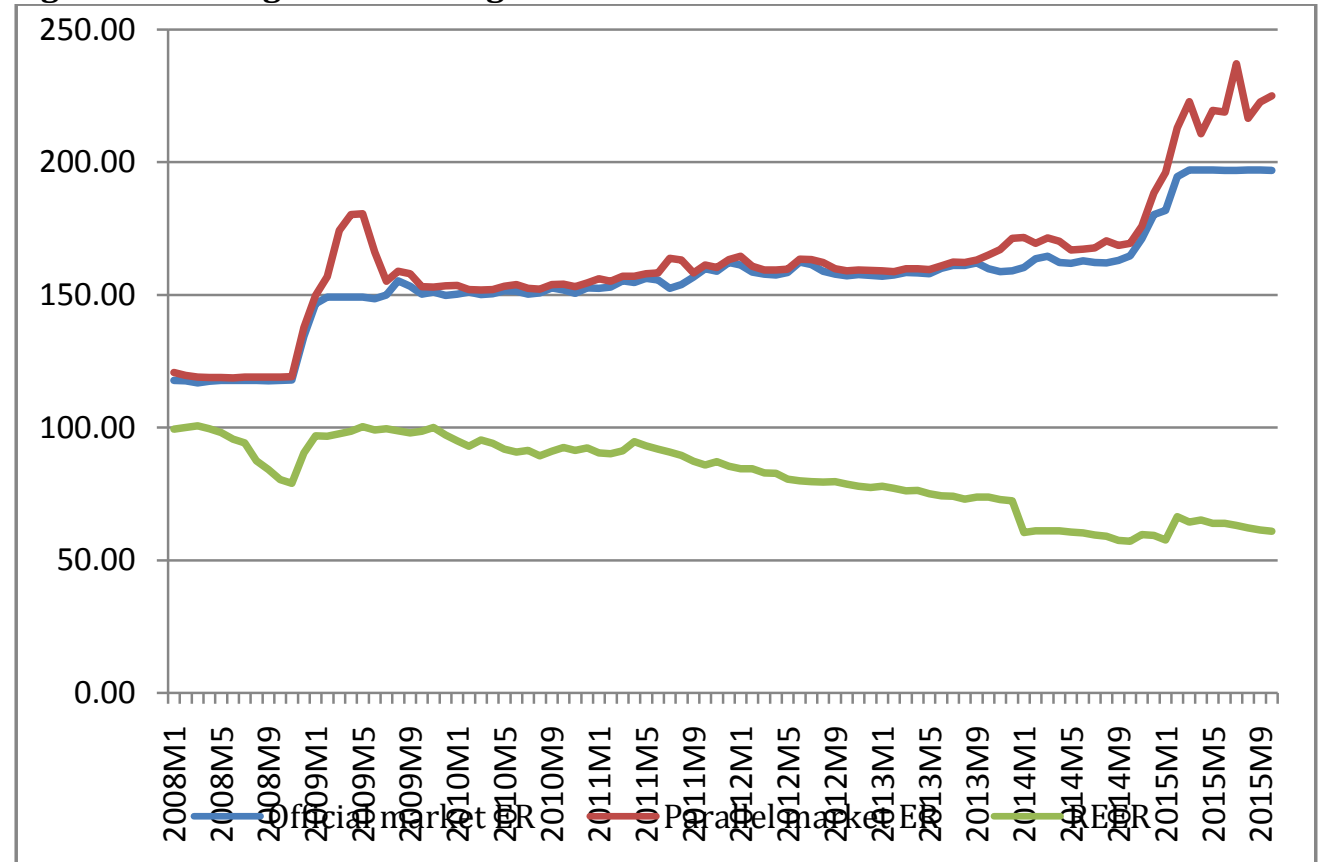

Source: Central Bank of Nigeria Statistics Database

In accordance with contemporary literature, we adopt a non-linear approach to our study, given previous observations that effects of increases in oil price are more significant than the effects of decrease in the same on the macro economy, and as such, linear oil price data may not adequately capture the oil price dynamics (Mork, 1989; Lee \& Ratti, 1995; Hamilton, 1996; Jiménez-Rodríguez and Sánchez, 2005). A theoretical basis of the non-linear modelling of oil price changes is hinged upon the dispersion hypothesis formulated by Lilien (1982). ${ }^{4}$ This paper extends the empirical literature by providing evidence on the exchange rate dynamics on a crude oil net-exporting but import dependent (especially in the area of refined oil products) country, given the pass-through effects of falling foreign reserves and escalating domestic prices. Our findings support previous empirical literature relating to the significance of oil prices for the exchange rate movements but deviate from theoretical and empirical literature as regards the nature of asymmetric effects of shocks in oil price. Specifically, increases in oil price have no significant effects on the real effective exchange rate while decreases in oil price have significant appreciation effects on the real effective exchange rate in Nigeria. Our findings identify the inflationary tendencies in the economy as a link through which oil prices cause the observed real effective exchange rate appreciation effects. This is particularly in view of the high import dependency of Nigeria, especially for scarce petroleum products and the potential pass-through effects of rising nominal exchange rates on local prices. The rest of the paper is structured as follows. We review the

${ }^{4}$ Summarily, the hypothesis holds that as a result of the high cost involved in the reallocation of resources in the short run, oil shocks which bring about readjustment between energy-intensive and energy-efficient sectors will lead to an overall decline in output. 
empirical literature in Section 2; In Section 3, we present the data and methodology; In Section 4, we present the empirical results of the study; and finally, we make concluding remarks and recommendations in Section 5 .

\section{Empirical Literature Review}

The empirical literature on the oil price-exchange rate nexus is classified into four groups. The first group includes studies that find causality running strictly from oil prices to real exchange rate such as Amano and van Norden for the U.S. (1998a), and Germany and Japan (1998b); Akram (2004) for Norway; JiménezRodríguez and Sánchez (2005) for a group of OECD countries; Olomola and Adejumo for Nigeria (2006); and Volkov and Yuhn (2013) for a selection of oil exporting countries. The second group consists of studies that find causality running strictly from real exchange rate to oil prices such as Sadorsky (2000) for crude oil future prices in the U.S.; Yousefi and Wirjanto (2004) for Iran, Indonesia, Saudi Arabia and Nigeria. The third group are those that find evidence of bi-directional causality between oil prices and real exchange rates. These include Jahan-Parvar, 2008 for Indonesia, Gabon, Saudi Arabia and Nigeria; and Yanagisawa, 2010 which previously finds two-way causal relationship for U.S.A. but implies lack of causality between exchange rate and oil price in the last year of study. Finally, the fourth group indicate neutrality, i.e., that there is no causality between the variables, suggesting that oil prices and exchange rates have no predictive ability toward other. Examples of such include studies by Bjornland and Hungnes (2008) and Habib and Kalamova (2007) for Norway; Habib and Kalamova 2007 for Saudi Arabia; and Şahbaz, Adıgüzel, Bayat and Kayhan for a non-linear relationship in the case of Romania. Specific to the Nigerian context, Olomola and Adejumo (2006) investigate the nexus between oil price changes and macroeconomic variables, including the real exchange rate, in Nigeria between 1970 and 2003 using quarterly data. They find that while oil price shocks have no effect on inflation and output, high increases in oil price may give rise to real exchange rate appreciation. Also, Aliyu (2009) considers the real exchange rate as a link through which oil price changes affect the GDP using the non-linear approach. He obtains the result that oil prices result in real exchange rate appreciation. Lastly, Adeniyi et al. (2012) find that a $100 \%$ increase in oil price returns leads to about $1.1 \%$ appreciation of the Naira in terms of the US dollar. They however, make use of the nominal exchange rate variable in conducting their analysis. The implication of changing oil prices for the competitiveness of the Naira via the real effective exchange rate is not yet well explored.

\section{Data and Methodology}

We make use of a monthly five-variable vector autoregressive (VAR) model for the study, consisting of real effective exchange rate (REER), the Bonny light crude oil price, all share index (ASI), interest rate, and inflation rate. REER, oil price and ASI are represented in logs, while the other two variables are expressed in levels. Oil prices and REER are included since our primary objective is to investigate the effects of the first on the second. The only variable capturing economic activity is the ASI of the Nigerian Stock Exchange (NSE). This is used as monthly data were not available for real GDP at the time of the study. Interest rate and inflation rate are included with a view to capturing important channels through which oil prices or policy might affect REER indirectly. For instance, REER could react to movements in interest rate and inflation rate. Interest rate is proxied by the 91-day Treasury-Bill rate as a measure of the monetary policy conditions while inflation rate is represented by the year-on-year rate. Apart from ASI which is obtained from the NSE, all the other data are obtained via the Central Bank of Nigeria (CBN) Statistics Database. The monthly data ranges from January, 2008 to October, 2015 - a total of 94 observations. Following Jiménez-Rodríguez and Sánchez (2005), we adopt the VAR model of order $p$ (VAR $(p)$ ):

$y_{t}=c+\sum_{i=1}^{p} \Phi_{i} y_{t-i}+\varepsilon_{t}$

where $y_{t}$ is a $(n \times 1)$ vector of endogenous variables, $c=\left(c_{1}, \ldots, c_{5}\right)^{\prime}$ is the $(5 \times 1)$ intercept vector of the $\mathrm{VAR}, \Phi_{i}$ is the $\mathrm{i}^{\text {th }}(5 \times 5)$ matrix of autoregressive coefficients for $i=1,2, \ldots, p$, and $\left(\varepsilon_{1 t}, \ldots, \varepsilon_{5 t}\right)^{\prime}$ is the $(5 \times 1$ ) representation of a white noise process. 
Before we start with our empirical analysis, we investigate the stochastic properties of our variables by analysing their orders of integration through the Augmented Dickey-Fuller (ADF) and Phillips-Perron (PP) tests. ${ }^{5}$ The tests' results are discussed in the next section. Our VAR system is converted into its Moving Average (MA) form in order to analyse the response of the system to oil price shocks as follows:

$$
y_{t}=\mu+\sum_{i=0}^{\infty} \Omega_{i} \varepsilon_{t-i}
$$

where $\Omega_{i}$ represents the identity matrix, and $\mu$ represents the mean of the process. The MA process is used to achieve both the impulse-response functions and the forecast error variance decompositions.

We examine the orthogonalised impulse-response functions, using Cholesky decomposition and accumulated responses to assess the impact of shocks on endogenous variables. To achieve this, it is essential to choose an ordering for the variables in the system, since the method of orthogonalisation entails the assignment of contemporaneous correlation to particular variables. Essentially, while shocks to the first variable affects the subsequent variables in the system, shocks to the subsequent variables do not contemporaneously affect the first variable; likewise, while the second variable contemporaneously affects the subsequent variables (except the first one), it is not contemporaneously affected by the subsequent variables; and so forth. Specifically, we assume the following ordering: REER, oil price, ASI, interest rate, and inflation rate. We operationalize (3.1) by estimating a linear specification as well as consider three non-linear transformations of oil price. ${ }^{6}$ The nonlinear transformations are as follows: 1) asymmetric specification, involving the separate consideration of oil price increases and decreases; 2) scaled specification, which captures oil price volatility; and 3) net specification in which the respective oil prices are defined as the net aggregate by which the prices in month $t$ surpass the maximum amount attained in the preceding twelve months. ${ }^{7}$ The linear oil price variable, which assumes symmetry, is defined as the monthly oil price returns thus:

$O_{t}=\log \left(\frac{x_{t}}{x_{t-1}}\right)$

where $x_{t}$ and $x_{t-1}$ refer to the current and one period lag of the nominal oil price, respectively.

The asymmetric specification disaggregates the linear rates of change specification of oil price (3.3) into its positive $\left(O_{t}^{+}\right)$and negative $\left(O_{t}^{-}\right)$components as follows:

$$
\begin{aligned}
& O_{t}^{+}=\left\{\begin{array}{cc}
O_{t} & \text { if } O_{t}>0 \\
0 & \text { otherwise }
\end{array}\right. \\
& O_{t}^{-}= \begin{cases}O_{t} & \text { if } O_{t}>0 \\
0 & \text { otherwise }\end{cases}
\end{aligned}
$$

The model is based on the dispersion hypothesis advanced by Lilien (1982), which holds that both positive and negative changes in price may affect the marginal product of resource inputs and bring about sectoral allocation of productive factors on the supply side of the economy. Bernanke (1983) further suggests that the volatility created by oil price changes may create investment and consumption uncertainties which have consequences for economic growth. Based on this idea, other non-linear specifications such as the scaled and net models were advanced. The scaled specification was introduced in Lee \& Ratti (1995) to take account of the idea that increases in oil price after an extended period of price stability have more intense macroeconomic effects than decreases in oil price during the preceding quarter. To operationalize this, the following AR (4)-GARCH $(1,1)$ formulation of oil prices was proposed:

$$
O_{t}=\alpha_{0}+\alpha_{1} O_{t-1}+\alpha_{2} O_{t-2}+\alpha_{3} O_{t-3}+\alpha_{4} O_{t-4}+e_{t}
$$

\footnotetext{
${ }^{5}$ Details of the tests are provided in Dickey and Fuller (1979) and Phillips and Perron (1988).

${ }^{6}$ However, we use nominal oil price, following Hamilton (1996), unlike Jiménez-Rodríguez and Sánchez (2005) who use the real price of oil.

${ }^{7}$ This is an adaptation of Hamilton (1996) where the previous four quarters were used.
} 


$$
\begin{aligned}
& e_{t} \mid I_{t-1} \sim N\left(0, h_{t}\right) \\
& h_{t}=\gamma_{0}+\gamma_{1} e_{t-1}^{2}+\gamma_{2} h_{t-1} \\
& S O P I_{t}=\max \left(0, \hat{e}_{t} / \sqrt{\hat{h}_{t}}\right) \\
& \operatorname{SOPD}_{t}=\min \left(0, \hat{e}_{t} / \sqrt{\hat{h}_{t}}\right)
\end{aligned}
$$

where SOPI and SOPD represent scaled oil price increases and decreases, respectively. The scaled model is a modification of the asymmetric model. It involves a process of transforming the residual and ARCH effects derived from the oil price model. This transformation addresses the frequent fluctuations in oil prices, which consists of mostly small changes and occasional large shocks.

The net specification (NOPI) developed by Hamilton (1996) is defined as the amount by which (the logged) oil prices in quarter $t, p_{t}$ surpass the maximum value over the preceding 4 quarters; and 0 otherwise. Given that we use monthly data in this study, we use the following modification of the proposed specification:

$N O P I_{t}=\max \left\{0, p_{t}-\max \left\{p_{t-1}, p_{t-2}, \ldots, p_{t-12}\right\}\right\}$

This definition is also asymmetric as it captures the increase-type shocks where as ignoring the effect of decreases in oil price. This follows previous evidence that oil price decreases had a less significant effect on the US macro economy.

\section{Empirical Results}

In this section, we evaluate the empirical findings from the linear and non-linear models discussed in the earlier section. First, we report the results of our unit root tests in subsection 4.1. In subsection 4.2, we test for the significance of the different oil price variables and perform multivariate and bivariate Grangercausality analysis. Subsequently, in subsection 4.3, we analyse the effects of oil price shocks on REER after comparing the performance of the different specifications considered, emphasizing the results of the most preferred model based on different criteria. Next, we present results on impulse-response functions and accumulated responses. This is followed by the results of the variance decompositions. In order to find the appropriate lag length, we consider different tests such as Hannan-Quinn information criterion (HQ), Final prediction error (FPE), Schwarz information criterion (SC), Akaike information criterion (AIC), and the sequential modified Likelihood Ratio (LR) test. We choose 4 lags in all our regressions based on the LR test, following Hatemi-J and Hacker (2009). ${ }^{8}$

Unit root tests: The optimal lag length adopted in the unit root test is based on the Schwarz Criterion (SC). Results show that all our 5 variables are nonstationary at level but stationary at first difference, and thus, are integrated of order one (I (1)). All the non-linear oil price specifications are I (0). We therefore define the vector $y_{t}$ in equation (3.1) as the first log-differences of REER, the linear oil price, ${ }^{9}$ and ASI, along with the first differences of interest rate and inflation. ${ }^{10}$

Tests for significance and Granger-causality: In this subsection, we investigate the nexus between oil price shocks and real effective exchange rate by carrying out different tests for both our linear and non-linear specifications for Nigeria. First, we assess the significance of the oil price variable in question for the VAR system in general, given the null hypothesis that all the coefficients of oil price are jointly zero in all equations of the system except its own equation. We achieve this by carrying out the Likelihood Ratio (LR) test, which could be useful in helping us to determine whether oil prices do not affect real effective exchange rate directly, but via third variables in the system. As displayed in Table 2, we find that oil price specification in the linear model $\left(O_{t}\right)$, the decreases in the asymmetric model $\left(O_{t}^{-}\right)$, and the scaled oil price decreases

\footnotetext{
${ }^{8}$ The paper suggests the choice of LR when there is disagreement among the different tests.

${ }_{9}^{9}$ This is as specified in equation 3.3. In practice, we transform the nominal oil price by first differencing its logged level. The non-linear oil price variables, which are derived from our linear oil price specification, are used in their level forms since they are already I(0).

${ }^{10}$ We do not follow the alternative approach of estimating a cointegrated VAR where nonstationary variables are specified in levels.
} 
(SOPD) are the only significant oil price specifications. The non-linear increase models, that is, the increases in the asymmetric $\left(\mathrm{O}_{t}^{+}\right)$, scaled $\left(S O P I_{t}\right)$ and net $\left(N O P I_{t}\right)$ models are therefore eliminated from our final analysis as the LR test fails to detect their importance in our VAR system.

Table 1: Unit Root Tests

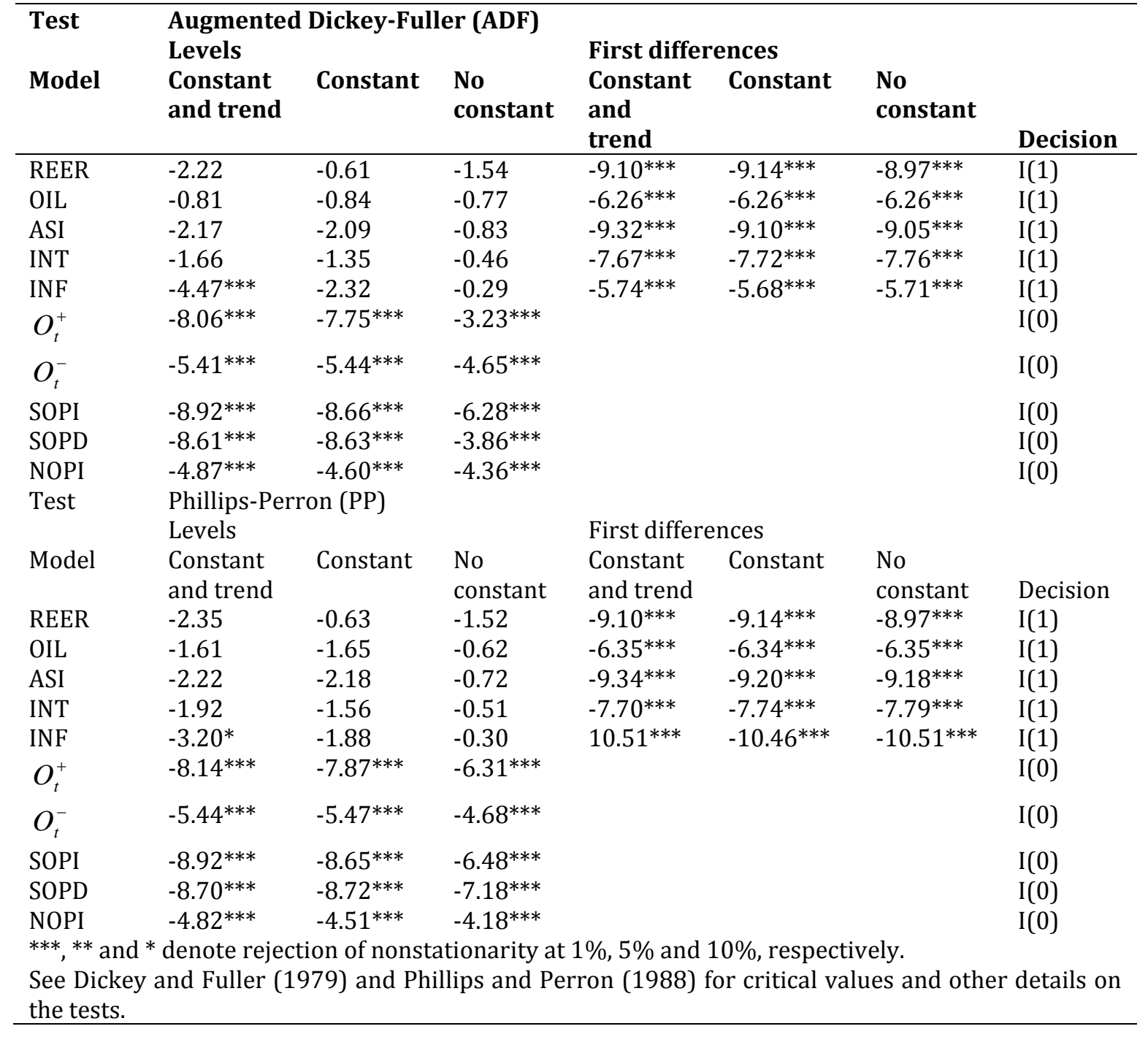

Table 3presents the results of the multivariate and bivariate Granger causality tests. The results are very consistent with the results of our LR tests as the models for which the oil price variable Granger-causes REER are same as those which passed the LR tests. In the multivariate context, we first test the null hypothesis that a given oil price variable does not Granger-cause REER (see Table 3, line 1), obtaining the result that oil price variables in the linear model, the negative changes in the asymmetric model $\left(O_{t}^{-}\right)$, and the scaled oil price decreases (SOPD) Granger-cause REER at a maximum significance level of 5\%. ${ }^{11}$ Second, we test the null hypothesis that the oil price variable in question is not Granger-caused by the remaining variables in the system (Table 3, line 2). We accept the null hypothesis in all the models. The bivariate Granger causality tests strongly support the results of the multivariate Granger causality tests. Specifically, $O_{t}, O_{t}^{-}$, and SOPD, Granger-cause REER (see line 3 of Table 3 ) at the 1\% significance level. The existence of reverse causality

11 The positive oil price changes in the asymmetric specification, the positive changes in the scaled specification (SOPI), and the positive changes in the net specification (NOPI) do not Granger-cause real effective exchange rate. 
from REER to the different oil price specifications is totally rejected, thus confirming that the oil price variables are exogenous while REER is endogenous within the VAR system.

\section{Table 2: Likelihood Ratio Test}

We rewrite the $p$-th order VAR model as follows:

$y_{1 t}=k_{1}+D_{1}{ }^{\prime} x_{1 t}+D_{2}{ }^{\prime} x_{2 t}+\varepsilon_{1 t}$

$y_{2 t}=k_{2}+C_{1}{ }^{\prime} x_{1 t}+C_{2}{ }^{\prime} x_{2 t}+\varepsilon_{2 t}$

where $y_{1 t}$ represents the vector of variables other than $y_{2 t}, x_{1 t}$ comprises lags of $y_{1 t}, y_{2 t}$ denotes the respective real oil price change, and $x_{2 t}$ comprises lags of $y_{2 t}$.

$H_{0}$ : All coefficients of oil price are jointly zero in all equations of the system except its own equation, i.e. $D_{2}=0$.

The statistic is defined as:

$$
2 \times\left[L\left(\theta_{1}\right)-L\left(\theta_{2}\right)\right] \sim^{a} \chi^{2}\left(\operatorname{rows}\left(y_{t}\right) \times p\right)
$$

where $L\left(\theta_{1}\right)$ indicates the value of the log-likelihood function of the unrestricted model while $L\left(\theta_{2}\right)$ indicates that of the restricted model.

We report $p$-values of the asymptotic distributions for the different specifications as follows:

\begin{tabular}{llllll} 
LINEAR & ASYMMETRIC & \multicolumn{3}{c}{ SCALED OIL PRICE } & NET OIL PRICE \\
$O_{t}$ & $O_{t}^{+}$ & $O_{t}^{-}$ & $S O P I_{t}$ & $S O P D_{t}$ & $N^{*}$ \\
$0.005^{* * *}$ & 0.384 & $0.000^{* * *}$ & 0.288 & $0.001^{* * *}$ & 0.305
\end{tabular}

*** and ${ }^{* *}$ denote rejection of the null hypothesis at $1 \%$ and $5 \%$ levels of significance, respectively.

Table 3: Multivariate (Block-Exogeneity) and Bivariate Granger Causality Tests

Notes: For the block exogeneity test within our VAR specification, we specify the $p$ th-order equations of REER and the respective oil price variables as follows:

$$
\begin{aligned}
& y_{1 t}=c_{1}+A_{1}{ }^{\prime} x_{1 t}+A_{2}{ }^{\prime} x_{2 t}+\varepsilon_{1 t} \\
& y_{2 t}=c_{2}+B_{1}{ }^{\prime} x_{1 t}+B_{2}{ }^{\prime} x_{2 t}+\varepsilon_{2 t}
\end{aligned}
$$

where $y_{1 t}$ is REER, $y_{2 t}$ represents the respective oil price variable, $x_{1 t}$ is the vector containing lags of $y_{1 t}$ and other explanatory variables, and $x_{2 t}$ is a vector containing lags of $y_{2 t}$.

$y_{1}\left(y_{2}\right)$ is block-exogenousin relation to $y_{2}\left(y_{1}\right)$ when $A_{2}=0\left(B_{1}=0\right)$.

$A_{2}$ represents $\chi^{2}$ (Wald) statistics for the joint significance of all of the lagged oil price variable, while $B_{1}$ represents $\chi^{2}$ (Wald) statistics for all the other lagged endogenous variables.

$\begin{array}{llll}\text { TESTS } & \text { LINEAR } & \text { ASYMMETRIC } & \text { SCALED OIL PRICE } \\ & O_{t} & O_{t}^{-} & \text {SOPD } \\ \text { Granger causality/Block } & 12.332^{* *} & 20.803^{* * *} & 16.565^{* * *} \\ \text { exogeneity tests }\left(A_{2}=0\right) & (0.015) & (0.000) & (0.002) \\ \text { Granger causality/Block } & 13.659 & 9.151 & 12.527 \\ \text { exogeneity tests }\left(B_{1}=0\right) & (0.624) & (0.907) & (0.707) \\ \text { Bivariate Granger causality } & 4.922^{* * *} & 6.947^{* * *} & 6.787^{* * *} \\ \left(H_{0}: \text { Oil price does not }\right. & (0.001) & (0.000) & 0.000)\end{array}$

Granger-cause REER) 


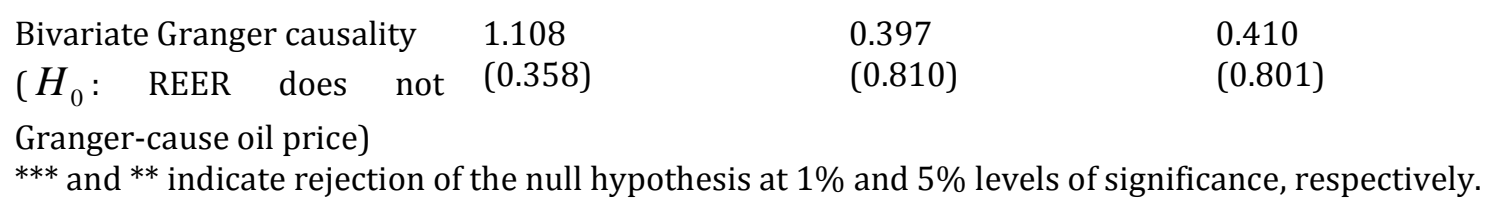

The causality tests generally reflect a direct effect of oil prices on the exchange rate. Among the other variables, only inflation Granger-causes REER at less than $10 \%$ significance level. This is plausible, given the inflation-real exchange rate relationship. Summarily, the causal relationship between the oil price variables and REER goes in one direction between the former and the latter. Furthermore, the multivariate Granger causality and bivariate Granger causality tests reveal the interesting result that while the linear oil price variable Granger-causes real effective exchange rate, the causal effect is dominated by negative as against positive oil price shocks.

Oil price shocks and real effective exchange rate: Linear and non-linear effects: In this subsection, we scrutinize empirically the effects of oil price shocks on REER. The causality tests carried out in the earlier section have shown that oil prices have a direct causal impact on REER. We therefore, focus mainly on the impulse response functions relating to the oil price variables. We report the results only for the models that passed our LR test, which incidentally, are the models for which our Granger-causality tests find a one-way causal relation between oil price shocks and REER; namely, the linear oil price variable $\left(O_{t}\right)$ and the nonlinear negative changes in oil price, that is, the asymmetric decreases in oil price $\left(O_{t}^{-}\right)$and SOPD. We emphasize the results obtained for the asymmetric decreases in oil price, which is our preferred model. We arrive at our choice of preferred model in two different ways, following Jiménez-Rodríguez and Sánchez (2005). First, we gauge the precision of the impulse responses by observing the confidence bands as presented in Figures 2, 3 and 4. Second, we observe selection criteria such as the Schwarz Criterion (SC) and Akaike Information Criterion (AIC), for which the asymmetric decrease model has the lowest values in our VAR system as shown in Table $4 .{ }^{12}$

Table 4: Choice of Preferred Model

\begin{tabular}{llll}
\hline CRITERION & LINEAR $\left(O_{t}\right)$ & ASYMMETRIC $\left(O_{t}^{-}\right)$ & SCALED $\left(S O P D_{t}\right)$ \\
\hline Schwarz (SC) & -3.246 & $\mathbf{- 3 . 3 4 6}$ & -3.297 \\
Akaike (AIC) & -3.833 & $\mathbf{- 3 . 9 3 3}$ & -3.884 \\
\hline
\end{tabular}

Impulse response functions and accumulated responses: In this subsection, we study the effects of oil prices on REER looking at both the orthogonalised impulse response functions and the accumulated responses for the linear and non-linear models. Figures 2, 3 and 4 represent the orthogonalised impulse response functions of REER to the one standard deviation oil price shock variables bordered by their respective two standard error bands. ${ }^{13}$ Table 5 reports the accumulated responses of REER to shocks in the respective oil price variables normalised to correspond to $1 \%$ increase and decrease in the linear and nonlinear models, respectively. Regarding the orthogonalised impulse responses, we observe a general pattern in the reaction of REER to the shocks in oil price variables. Taking our preferred (asymmetric) model, there is a negative response within the first three months followed by a very brief positive response in the fourth month, which reverts to negative almost immediately. The negative response is sustained until the seventh month, after which there is a positive response until the effects of the shock disappear entirely by the thirteenth month. The largest negative impact on REER occurs in the fifth month.

\footnotetext{
12 Jiménez-Rodríguez and Sánchez (2005) and Hamilton (2003), however, favoured the scaled specification. Nevertheless, our scaled specification also performs well, ranking next to the asymmetric specification ahead of the linear model based on SC and AIC.

${ }^{13}$ The two standard error bands bordering the impulse responses follow Lutkepohl (1990).
} 
Table 5: Accumulated Response of the Rate of Change in REER to a 1\% Oil Price Shock

\begin{tabular}{llll}
\hline MONTHS & LINEAR $\left(O_{t}\right)$ & ASYMMETRIC $\left(O_{t}^{-}\right)$ & SCALED $\left(S O P D_{t}\right)$ \\
\hline 4 & -0.01444 & $\mathbf{- 0 . 0 1 7 0 0}$ & -0.00879 \\
8 & -0.02534 & $\mathbf{- 0 . 0 3 0 3 6}$ & -0.02460 \\
12 & -0.01780 & $\mathbf{- 0 . 0 2 4 1 9}$ & -0.01969 \\
16 & -0.01889 & $\mathbf{- 0 . 0 2 4 3 4}$ & -0.02053 \\
20 & -0.01939 & $\mathbf{0 . 0 2 4 2 6}$ & -0.01984 \\
24 & -0.01948 & $\mathbf{0 . 0 2 4 6 9}$ & -0.02023 \\
\hline
\end{tabular}

The negative impact of the oil price decreases on REER significantly exceeds the positive impact. Consequently, the accumulated effect of oil price decreases is negative as shown for $O_{t}^{-}$in Table 5. Following a $100 \%$ negative oil price shock, the negative impact, which reaches its maximum of $3 \%$ by the eighth month, shows an accumulated figure of $2.5 \%$ by the end of the second year. Moreover, the negative effect of oil price decreases is evident in the linear and scaled models as they also reveal accumulated negative impacts of oil price shocks on REER. Also, the accumulated impulse responses of REER to inflation are negative as shown by the asymmetric decrease model in Figure 5.

Variance decomposition analysis: Table 6 presents the results of the forecast error variance decomposition, which indicates the proportion of the unanticipated changes in the variables are accounted for by various shocks. The results suggest that oil price shocks constitute the most significant source of variability in REER of all the macroeconomic variables in the model. We also find that shocks to oil price variables seem to account for more of REER variability in non-linear specifications than in the linear specification. Specifically, asymmetric decreases in oil prices (within our preferred model in line 2 of Table 6) contribute the highest to the variability in REERby $21.85 \%$, followed by the scaled oil price variable and then, the linear oil price variable with $21.67 \%$ and $15.82 \%$ contributions to the variability in REER, respectively. Consistent with theory and as observed in our impulse response functions, inflation ranks next to oil price shocks among the contributors to the variability in REER with as high as $6.9 \%, 7.2 \%$ and $6.4 \%$ in the linear, asymmetric and scaled models, respectively.

Table 6: Estimated Variance Decomposition of Real Effective Exchange Rate at the 12-month horizon

\begin{tabular}{llllll}
\hline MODEL & REER & OIL PRICE & ASI & INT & INFL \\
\hline LINEAR $\left(O_{t}\right)$ & 73.06 & 15.82 & 1.80 & 2.41 & 6.91 \\
ASYMMETRIC $\left(O_{t}^{-}\right)$ & $\mathbf{6 6 . 1 0}$ & $\mathbf{2 1 . 8 5}$ & $\mathbf{1 . 9 0}$ & $\mathbf{2 . 9 7}$ & $\mathbf{7 . 1 7}$ \\
$\operatorname{SCALED}\left(S O P D_{t}\right)$ & 67.01 & 21.67 & 2.62 & 2.29 & 6.40 \\
\hline
\end{tabular}

It is also notable that oil price shocks also explain the highest amount of variability other than from the variable itself in economic performance as measured by the all share index. This is consistent with findings in previous works such as Jiménez-Rodríguez and Sánchez (2005).

Discussion of findings: The negative effects observed in the orthogonalised and accumulated impulse responses of REER to negative oil price shocks in our results indicate that decreases in oil price result in appreciation of the real effective exchange rate of the Naira. In other words, oil price decreases cause a reduction in the competitiveness of the Nigerian currency. This differs from the evidence for other oil exporting economies such as the UK and Norway where real appreciation of the real effective exchange rate is rather due to increases in oil prices (Jiménez-Rodríguez and Sánchez, 2005). Furthermore, the nonsignificance of our positive non-linear models reveal that periods of oil price hikes do not bring about significant responses in Nigeria's real effective exchange rate. Our findings are not surprising considering the fact that periods of high oil prices have not necessarily occasioned the expected effects on the Nigerian exchange rates(see Figure 1 in Section 1).

Our findings are reasonable in view of the escalating inflation rates occasioned by the country's high demand for import commodities in the presence of rising nominal exchange rates. Indeed, the theory on exchange rate 
stipulates that the real exchange rate should fall (appreciate) in response to increases in domestic prices. This is evident in our results, as depicted in Figure 5 in which the accumulated impact of REER to positive shocks in inflation is negative by the end of the second year, and given the relatively large amount of variability in REER accounted for by inflation in our variance decomposition analysis. We may therefore suggest a link between Naira depreciation and the real effective exchange rate appreciation through a pass-through effect on domestic prices. This is in view of the fact that Nigeria's foreign reserves are largely dependent on proceeds from oil exports. Falling oil prices lead to gradual depletion of the foreign reserves with consequent nominal exchange rate depreciation. However, the behaviour of the real effective exchange rate is different from that of the nominal exchange rate given the escalation of domestic prices in the import-dependent economy. It is worth noting that the inflationary tendencies have been exacerbated by the scarcity and hence, high importation costs of refined crude oil products, mainly petrol.

\section{Conclusion and Recommendations}

Against the background that oil price increases should stimulate exchange rate appreciation in oil exporting countries, this paper examines the impact of oil price shocks on exchange rate movements in Nigeria. We focus mainly on the relationship between oil prices and real effective exchange rate so as to explore the competitiveness of the Nigerian currency. The study involves recent periods of financial and economic crises - 2008(M1) - 2015(M10), and is analysed in terms of a vector autoregressive approach based on a linear and three non-linear specifications widely adopted in the oil price literature. While the linear specification assumes that oil price shocks have symmetrical impacts, the non-linear specifications explore the differential effects of increases and decreases in oil price. Our results reveal the existence of non-linear effects of oil prices, with our Granger-causality tests showing that causality runs strictly in one direction from oil prices to real effective exchange rate. Our five-variable VAR reveals that oil prices shocks constitute the most significant proportion of the variability in real effective exchange rate. The significance of inflation in the oil price-real effective exchange rate relationship is also emphasized given the sustained impact of inflation on real effective exchange rate in the impulse response functions and the relatively high contribution of shocks in the former to variability in the latter as observed in the variance decomposition analysis.

Our findings are consistent with studies such as Jiménez-Rodríguez and Sánchez (2005); Olomola and Adejumo (2006); Aliyu (2009); and Adeniyi et al. (2012) vis-à-vis the significant impact of oil price shocks on the exchange rate. However, our findings differ in the sense that oil price decreases rather than increases are the significant cause of exchange rate movements. Also, our study reveals that oil price shocks, largely based on the decreasing component, bring about real effective exchange rate appreciation rather than depreciation as against the results obtained in the previous studies within the Nigerian context. This implies that decreases in crude oil price weaken the competitiveness of the Naira compared to the currencies of her trade partners. These results are instructive considering the multi-country information captured by the real effective exchange rate as against the real exchange rate. The results of this study underscore the heavy reliance of the Nigerian economy on crude oil exports and the need for policymakers to diversify the productive base and foreign exchange sources of the economy. Secondly, a more flexible exchange rate policy may be adopted in order to ease domestic inflationary tendencies and improve the competitiveness of the Naira.

Acknowledgement: We wish to thank Dr. O.R. Olayeni for his constructive comments and technical advice.

\section{References}

Adeniyi, O., Omisakin O., Yaqub, J. \& Oyinlola, A. (2012). Oil Price-Exchange Rate Nexus in Nigeria: Further Evidence from an Oil Exporting Economy. International Journal of Humanities and Social Science, 2(8), 113-121.

Akram, Q. F. (2004). Oil Prices and Exchange Rates: Norwegian Evidence. Econometrics Journal, 7, 476-504.

Aliyu, S. U. R. (2009). Oil Price Shocks and the Macroeconomy of Nigeria: A Non-linear Approach. MPRA Paper.

Aliyu, S. U. R., Yakub, M. U., Sanni, G. K. \& Duke, O. (2009). Exchange Rate Pass-through in Nigeria: Evidence from a Vector Error Correction Model. MPRA Paper No. 25053. 
Amano, R. A. \& van Norden, S. (1998a). Oil Prices and the Rise and Fall of the US Real Exchange Rate. Journal of International Money and Finance, 17, 299-316.

Amano, R. A. \& van Norden, S. (1998b). Exchange Rates and Oil Prices. Review of International Economics, 6(4), 683-694.

An, L. \& Wang, J. (2011). Exchange Rate Pass-through: Evidence Based on Vector Autoregression with Sign Restrictions. Federal Reserve Bank of Dallas Globalization and Monetary Policy Institute Working Paper No. $\quad 70 . \quad$ Retrieved $\quad$ from http://www.dallasfed.org/assets/documents/institute/wpapers/2011/0070.pdf

Appleyard, D. R. \& Field, A. J. (jr). (2001). International Economics (4th ed.). McGraw-Hill Higher Education.

Bjornland, H. C. \& Hungnes, H. (2008). The Commodity Currency Puzzle. The IUP Journal of Monetary Economics, 2, 7-30.

Corden, W. M. (1984). Booming Sector and Dutch Disease Economics: Survey and Consolidations, 36, 359380.

Dickey, D. A. \& Fuller, W. A. (1979). Distribution of the Estimators for Autoregressive Time Series with a Unit Root. Journal of the American Statistical Association, 74, 427-431.

Habib, M. M. \& Kalamova, M. M. (2007). Are there Oil Currencies? The Real Exchange Rate of Oil Exporting Countries. European Central Bank Working Paper Series no. 839.

Hamilton, J. (1996). This is What Happened to the Oil Price-Macroeconomy Relationship. Journal of Monetary Economics, 38, 215-220.

Hamilton, J. (2003). What is an Oil Shock? Journal of Econometrics, 113, 363-398.

Hatemi, J. A. \& Hacker, S. (2009). Can LR Test be Helpful in Choosing the Optimal Lag Order in the VAR Model when Information Criteria Suggest Different Lag Orders? Applied Economics, 41(09), 1121-1125.

Jahan-Parvar, M. R. \& Mohammadi, H. (2008). Oil Prices and Real Exchange Rates in Oil-Exporting Countries: A Bounds Testing Approach. University Library of Munich no. 13435.

Jiménez-Rodríguez, R. \& Sánchez, M. (2005). Oil price shocks and real GDP growth: empirical evidence for some OECD countries. Applied Economics, 37(2), 201-228.

Krugman, P. (1983). Oil shocks and exchange rate dynamics. In N. B. Research, \& J. A. Frenkel (Ed.), Exchange Rates and International Macroeconomics (pp. 259 - 284). University of Chicago Press.

Lee, K., Ni, S. \& Ratti, R. (1995). Oil Shocks and the Macroeconomy: the Role of Price Variability. Energy Journal, 16, 39-56.

Lilien, D. (1982). Sectoral Shifts and Cyclical Unemployment. Journal of Political Economy, 90, 777-793.

Lutkepolh, H. (1990). Asymptotic Distributions of Impulse Responses, Step Responses, and Variance Decompositions of Estimated Linear Dynamic Models. Review of Economics and Statistics, 72, 53-78.

Mork, K. (1989). Oil Shocks and the Macroeconomy when Prices Go Up and Down: An Extension of Hamilton's Results. Journal of Political Economy, 97, 740-744.

Olomola, P. A. \& Adejumo A. V. (2006). Oil Price Shocks and Macroeconomic Activities in Nigeria. International Research Journal of Finance and Economics, 3, 28-34.

Phillips, P. C. B. \& Perron, P. (1988). Testing for a Unit Root in Time Series Regression. Biometrika, 75, 335346.

Sadorsky, P. (2000). The Empirical Relationship between Energy Futures Prices and Exchange Rates. Energy Economics, 22, 253-266.

Şahbaz, A., Adıgüzel, U., Bayat, T. \& Kayhan, S. (2013). The Relationship between Oil Prices and Exchange Rate: The Case of Romania. International Conference on Eurasian Economies, (pp. 33-40).

Volkov, N. I. \& Yuhn, K. H. (2013). Oil Price Shocks and Exchange Rate Movements. Electronic copy available at: http://ssrn.com/abstract=2577409.

Yanagisawa, A. (2010). Relationship among Crude Oil Prices, Share Prices and Exchange Rate. IEEJ.

Yousefi, A. \& Wirjanto, T. S. (2004). The Empirical Role of the Exchange Rate on the Crude Oil Price Formation. Energy Economics, 26, 783-799. 


\section{Appendix}

Figure 2: Orthogonalised impulse-response function of real effective exchange rate to a one-standarddeviation oil price innovation Linear specification $\left(O_{t}\right)$

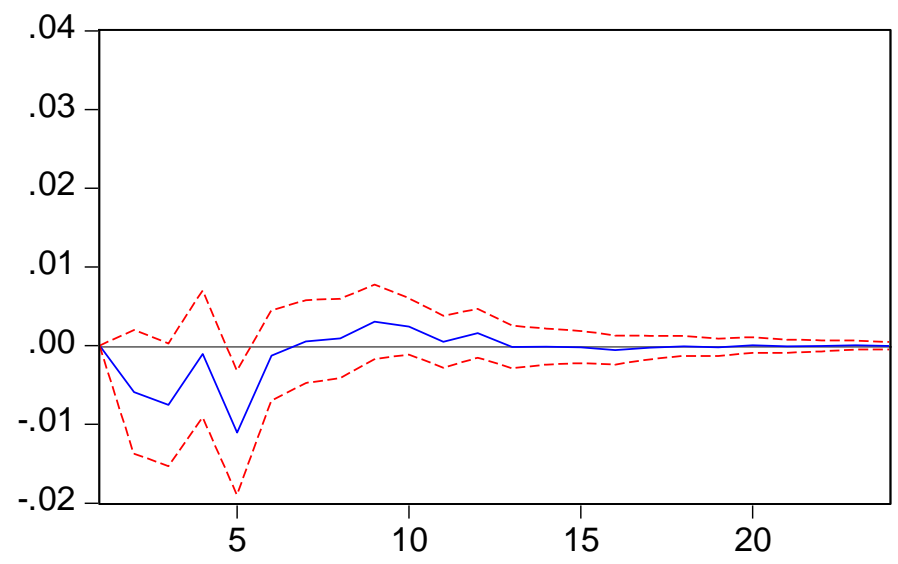

Figure 3: Orthogonalised impulse-response function of real effective exchange rate to a negative onestandard-deviation oil price innovation Asymmetric specification $\left(O_{t}^{-}\right)$

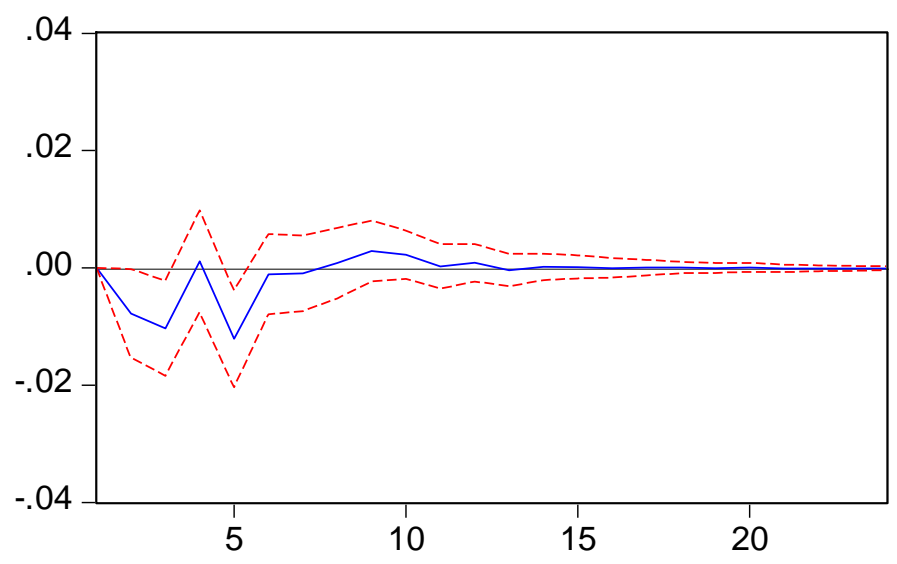

Figure 4: Orthogonalised impulse-response function of real effective exchange rate to a negative onestandard-deviation oil price innovation Scaled specification $\left(S O P D_{t}\right)$

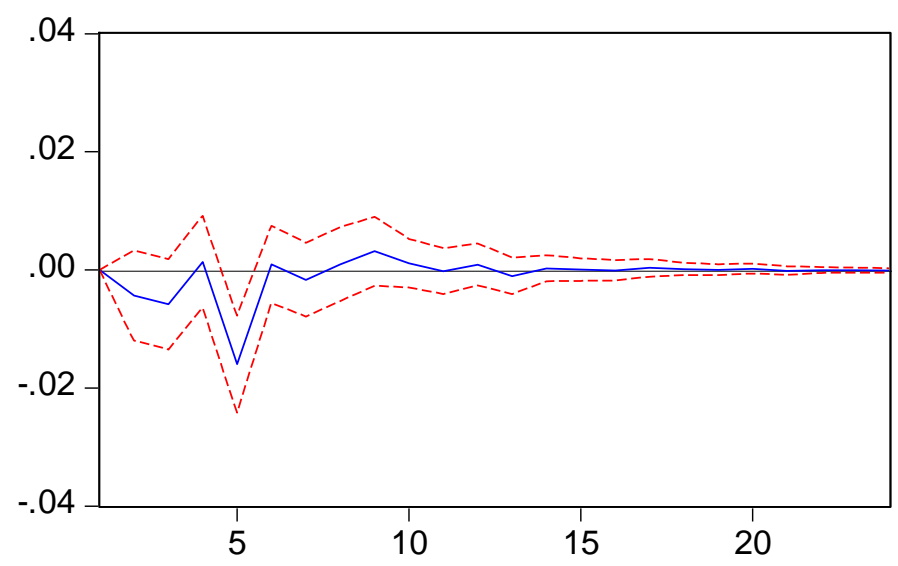


Figure 5: Accumulated impulse-response function of real effective exchange rate to a positive onestandard-deviation innovation in inflation Asymmetric specification $\left(O_{t}^{-}\right)$

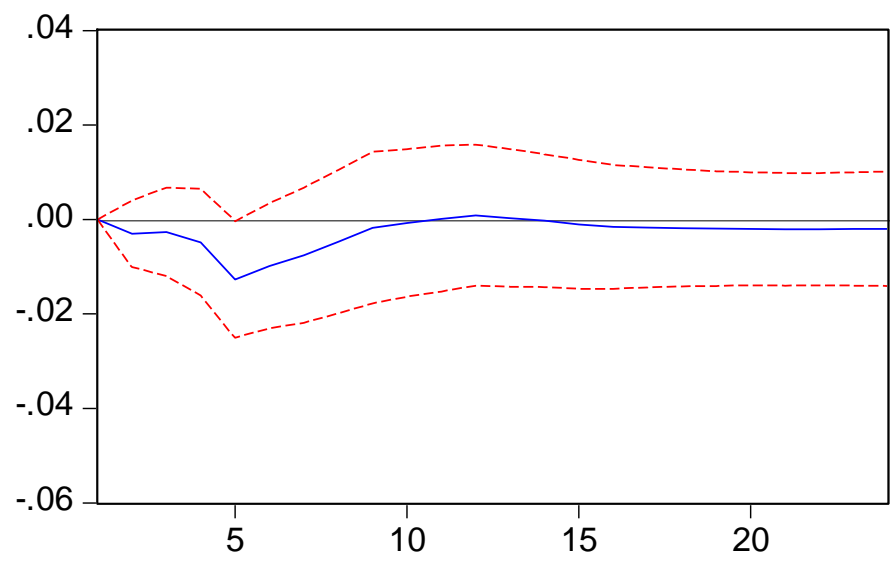

